\title{
Turismo rural no município de Paim Filho-RS/Brasil: potencialidades, alternativas e benefícios a partir da geração de trabalho e renda no espaço rural
}

\author{
Rosmari Cristina Schelle ${ }^{1}$, Elvis Albert Robe Wandscheer ${ }^{2}$, Tanice Andreatta ${ }^{3}$ \\ ${ }^{1}$ Bacharel em Administração Rural e Agroindustrial pela Universidade Estadual do Rio Grande do Sul/UERGS, Unidade em \\ Sananduva.E-mail rschelle@gmail.com \\ ${ }^{2}$ Geógrafo e Economista, Mestre em Desenvolvimento Rural/PGDR e Doutorando em Geografia pela Universidade Federal do Rio \\ Grande do Sul/UFRGS.E.mail: elvishz@yahoo.com.br \\ ${ }^{3}$ Doutora em Desenvolvimento Rural - PGDR/UFRGS e professora na área de Economia Rural na Universidade Federal do Pampa - \\ UNIPAMPA, Campus de Dom Pedrito/RS.E-mail: taniceandreatta@unipampa.edu.br
}

Recebido em 01/2012. Aceito para publicação em 04/2012.

Versão online publicada em 17/11/2012 (http://seer.ufrgs.br/paraonde)

\begin{abstract}
Resumo - 0 turismo rural vem se constituindo enquanto atividade potencial nas transformações na agricultura, oscilações de preços dos produtos agrícolas, problemas da sazonalidade, além dos riscos e incertezas em relação aos fatores de produção. Neste sentido, o trabalho visa identificar as potencialidades e dificuldades relacionadas a oferta do turismo rural em estabelecimentos agropecuários no município de Paim Filho-RS verificando os benefícios dessa atividade. A metodologia utilizada constou de pesquisa bibliográfica e posterior coleta de dados, aplicando-se questionários e entrevistas em 15 estabelecimentos rurais no município enfocado. Os resultados demonstram que os estabelecimentos abordados apresentam condições de serem explorados como produto turístico, seja através de suas belezas naturais, ou pelo estilo de vida que resguardam tradições e costumes. Entre os agricultores considerados, mais de $85 \%$ manifestaram interesse em seguir atuando no segmento do turismo rural, alguns inclusive já realizando investimentos em infraestrutura para receber visitantes. Salienta-se ainda que os atores locais são unânimes em considerar o turismo uma possibilidade de atividade complementar, que conjugada com outras atividades pode contribuir com a reprodução social da família. Em relação às limitações, existe a necessidade da realização de investimentos em infraestrutura e recursos humanos, além da ampliação da mão de obra. Concluiu-se que o turismo rural apresenta-se como alternativa potencial de geração de trabalho e renda, logo, poderia proporcionar benefícios aos estabelecimentos, tanto pela renda da atividade quanto pela comercialização de produtos agrícolas.
\end{abstract}

Palavras-chave: Turismo Rural. Potencial Turístico. Geração De Trabalho e Renda

\section{Introdução}

As mudanças pelas quais o mundo rural atravessou e ainda está sujeito a alterações apresentam mudanças de ordem demográfica, social e econômica. Estas mudanças se relacionam principalmente com a abertura do mercado nacional ao exterior, as exigências internas de consumo e o inerente aumento da competitividade dos mercados.

Além disso, os processos contemporâneos da relação campo-cidade têm levado a evolução acelerada dos centros urbanos e a industrialização, aspectos que induzem a migração da população rural para os pólos urbanos, onde se concentram importantes recursos econômicos (DIAS, 2003). Além disso, o processo histórico de evolução do campo privilegiaram grupos de agricultores dotados de mais recursos e com maior capacidade de aquisição e adaptação às tecnologias, o que levou a um aumento das desigualdades sociais no campo.

De um modo geral, os agricultores, sobretudo os agricultores familiares estão muito suscetíveis às oscilações dos preços dos produtos agrícolas, os problemas da sazonalidade e os riscos e as incertezas dos fatores de produção. Também vêm diminuindo o número de empregos no espaço rural e junto com ele o número de agricultores que nele permanecem. Os impactos dessa situação no mundo rural (principalmente após a década de 1980) intensificaram as discussões em torno de formas alternativas de geração, agregação e diversificação de atividades e ocupações vigentes no campo.

Este cenário é descrito por Caporal e Costa- 
beber da seguinte forma:

Passada a chamada década perdida, os anos 1990 começam com novas e grandes decepções para o povo brasileiro. A constituição de 1988, que trouxe a esperança de conquistas sociais importantes, continua sem ser regulamentada na maioria dos seus dispositivos. O Governo Collor, apresentado para a nação como tábua de salvação dos descamisados, acabou se transformando num pesadelo para as maiorias empobrecidas. 0 nível de desemprego, no campo e na cidade, assumiu taxas elevadíssimas, colocando em risco a estabilidade do tecido social. 0 êxodo rural continuou, tal como cresceu a concentração da posse da terra. As anunciadas super-safras não se refletiram em melhorias das condições de vida nem dos trabalhadores do campo, nem dos assalariados urbanos. A retirada dos subsídios à agricultura (embora ainda se beneficie de taxas inferiores às praticadas no mercado) desnudou o impasse das empresas rurais, cujas interpelações junto ao Estado são indicadores claros da sua dificuldade de manter a taxa de lucro que remunere o seu capital. A retração dos preços dos produtos agrícolas e a sua enorme defasagem em relação aos preços dos insumos e máquinas agrícolas colocam mais um entrave para a agricultura capitalista. (CAPORAL; COSTABEBER, 2004, p. 11).

Neste contexto, ainda na década de 1980 , surgem no Sul do Brasil iniciativas relacionadas ao Turismo Rural. De acordo com o Ministério do Turismo (2004, p. 15):

\begin{abstract}
Embora a visitação a propriedades rurais seja uma prática antiga e comum no Brasil, esse deslocamento para áreas rurais começou a ser encarada com profissionalismo na década de 1980, quando algumas propriedades em Santa Catarina e no Rio Grande do Sul, devido às dificuldades do setor agropecuário, resolveram diversificar suas atividades e passaram a receber turistas.
\end{abstract}

O fenômeno turístico por si só não consiste em uma atividade recente, da mesma forma que o turismo rural ${ }^{4}$ já apresenta uma vasta história de iniciativas bem sucedidas, muitas delas datam de experiências já do século XIX, na Europa, local em que o mesmo encontra-se, até os dias de hoje, mais avançado (RUSCHMANN, 2004).

Como atividade que perfaz uma das formas pela qual o espaço rural apresenta a sua diversificação espacial, "[...] 0 consumo do espaço é hoje um tema que renova os parâmetros da relação da sociedade com o seu espaço... A alma do rural mantém uma forte coloração agrícola, embora o bolso dependa, cada dia mais acentuadamente, de outros proventos [...] (BAPTISTA, 2006, p. 97 - 100)".

O Município de Paim Filho-RS (FIG. 1) é um exemplo de tal situação. Situado na encosta superior do Nordeste do estado do Rio Grande do Sul, próximo à região Alto Uruguai, possui uma área de $182,2 \mathrm{~km} 2$, distante 263,14 km da capital do estado do Rio Grande do Sul e uma população total de 4.243 habitantes, dos quais 1.990 (46,90\%) residem no território rural do município (IBGE, 2010).

Os seus principais pontos turísticos são: 0 Santuário Nossa Senhora do Caravaggio, onde é realizada a romaria no último domingo de maio de cada ano; a Gruta Nossa Senhora de Lourdes e o Balneário Espraiado (distante $4 \mathrm{~km}$ da sede).

Com características essencialmente agrícolas, configurado por pequenos estabelecimentos agropecuários, Paim Filho é um município eminentemente rural, e depende fortemente da agricultura e pecuária. Em função das sucessivas crises na agropecuária (principalmente devido a problemas climáticos) tem-se buscado o desenvolvimento de iniciativas capazes de diversificar atividades no campo. Assim, em virtude do município possuir aspectos gastronômicos e naturais, o mesmo pode ser explorado via turismo no espaço rural.

Institucionalmente o município se encontra incluído na Rota das Araucárias, uma associação turística da região nordeste do Estado. Criada em 2001, esta associação abrange em torno de 20 municípios da região, porém essa rota ainda é desconhecido por grande parte da população da região, bem como do estado do Rio Grande do Sul. Esta modalidade de turismo ainda é pouco explorada localmente, dentre outras causas, devido à falta de trabalhos e projetos de longo prazo.

Neste contexto, o objetivo deste trabalho consiste em analisar a realidade das propriedades rurais e o perfil dos agricultores do Município de Paim Filho, detendo-se nas especificidades dos estabelecimentos que tem potencialidades turísticas, assim como a disposição dos proprietários em seguir desenvolvendo a atividade. Buscou-se ainda captar as percepções dos agricultores sobre os interesses, as potencialidades e dificuldades para

\footnotetext{
${ }^{4}$ Por turismo rural compreende-se: “[...] uma expressão empregada, geralmente, de modo extensivo a qualquer atividade turística no espaço rural. Identifica-se com Turismo no Espaço Rural e Turismo nas Áreas Rurais, ambos os termos utilizados como sinônimos (TULIK, 2003)". Deve-se ressaltar que o turismo rural como fenômeno, apresenta-se como uma potencial alternativa para muitos espaços rurais, e vem cada vez mais crescendo em proporção e importância, à medida que permite a valorização do meio rural, tanto por meio do apelo à natureza e seus potenciais paisagísticos.
} 
sua atuação nesse segmento.

Para alcançar os objetivos propostos, o percurso metodológico contemplou a aplicação de questionários e entrevistas junto a agricultores (as) familiares de 15 estabelecimentos rurais no município de Paim Filho. A amostra utilizada foi não probabilística. Este tipo de amostra divide-se em acidental e intencional. A amostragem escolhida foi intencional, pois consistiu em: "[...] selecionar um grupo de elementos considerados típicos, em função das variáveis estudadas [...] 0 critério da escolha, neste tipo de amostra, é a razão e não o aleatório, mas a razão é fundada nos critérios préestabelecidos (ALMEIDA, 1989, p. 87)".

Assim, a seleção da amostra levou em consideração uma pesquisa exploratória antecedente a aplicação dos instrumentos quali-quantitativos onde foram identificados os estabelecimentos que possuem e apresentam potencialidades relacionadas aos aspectos naturais e/ou gastronômicos, assim como aspectos relacionados aos modos de vida dos agricultores, características que vem sendo exploradas como atrações turísticas no meio rural.

Dessa forma, o presente trabalho buscou evidenciar possibilidades e debilidades no que se refere à prática do turismo rural em estabelecimentos rurais no município de Paim Filho. Neste contexto, buscou-se compreender a atividade como contribuição a agregação de renda das respectivas famílias, bem como a inserção local em um conjunto de ações que podem contribuir significativamente para práticas viáveis e sustentáveis no longo prazo, fornecendo assim alternativas socioeconômicas a esse espaço rural.

Por fim, destaca-se ainda a utilização do software ArcView 3.2, utilizado na elaboração do mapa de localização da área em estudo, cumprindo as exigências normativas cartográficas.

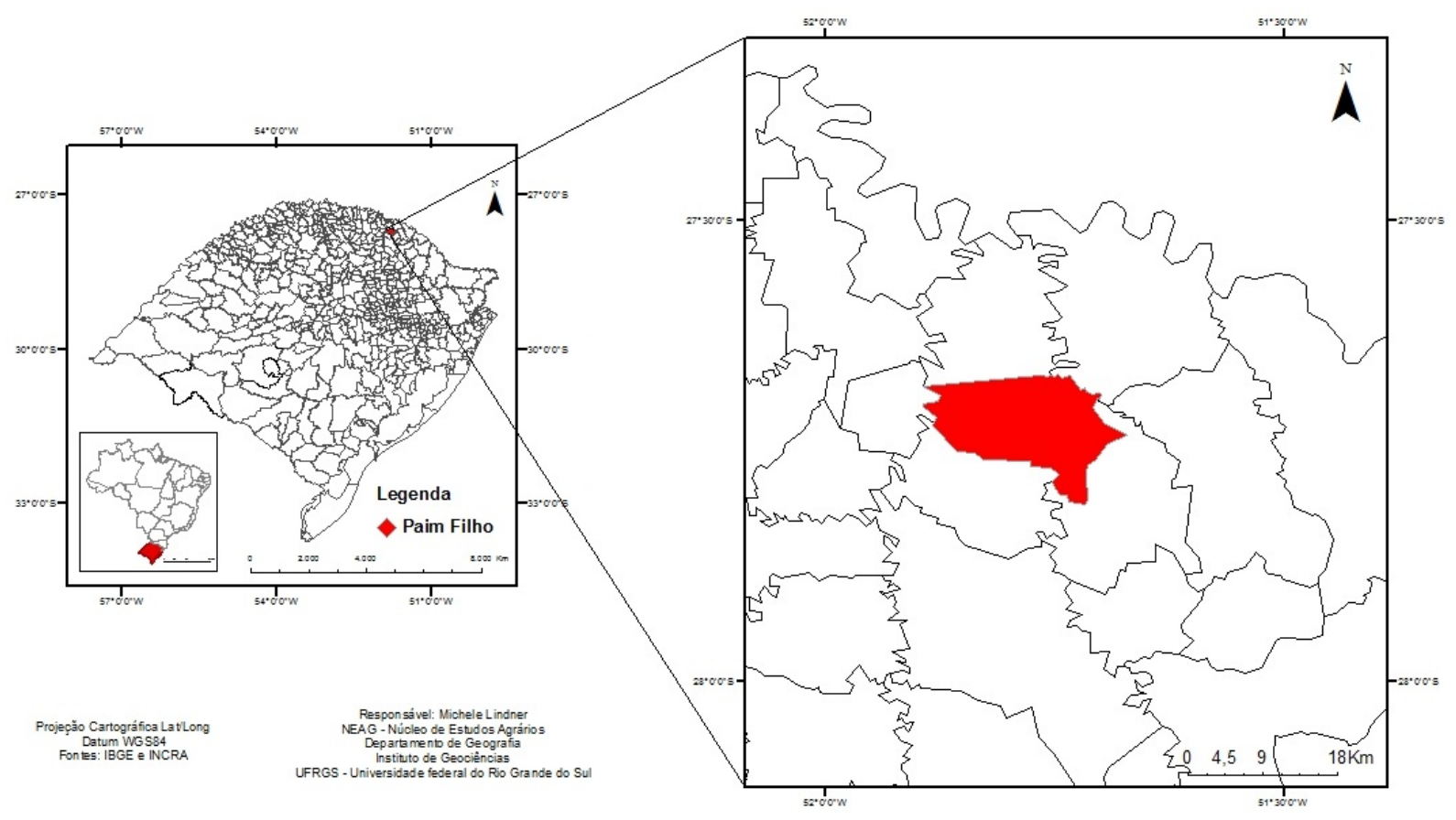

Figura 1. Mapa de localização da área em estudo. Fonte: IBGE (2012). Organização: Os Autores.

Desenvolvimento e turismo rural: reflexões teóricas acerca do papel da atividade turística no espaço rural

Com a globalização mundial e a difusão das tecnologias, o discurso hegemônico (atrelado à ideologia neoliberal) emergiu e efervesceu no pósguerra, é bem verdade que, sobretudo a partir do final do século XX, tal discurso (ainda que hegemônico no campo político) passou a conviver com uma série de críticas, muitas das quais alavancam novas visões, dentre as quais se encontram iniciativas inovadoras e valorativas de espaços naturais e culturais. Estes espaços até então desvalorizados, marcadamente no âmbito do rural, representavam locais potenciais ao êxodo rural, mas que atualmente são focos de alternativas e novas acepções que culminam não apenas com a redução do abandono do campo, mas também como (re)construção do patrimônio histórico-cultural-produtivo constituído nas propriedades rurais.

Na abordagem do presente trabalho, em se 
tratando de desenvolvimento rural ${ }^{5}$, existe a necessidade de primeiramente compreender o espaço rural e suas distintas facetas contemporâneas. Inicialmente enfatiza-se a transformação pela qual este espaço metamorfoseou-se com a modernização da agricultura através da Revolução Verde ${ }^{6}$, onde a produção passou a incorporar uma série de insumos e maquinários à esfera produtiva, ação que atinge por consequência todas as demais esferas que perfazem o mundo rural. Para Wanderley (2009, p. 206-211) a concepção de mundo rural nas sociedades modernas abarca uma série de diversidade e aspectos que divergem em distintos países, regiões e até mesmo localidades, em função dos processos históricos e a apropriação constituída no mesmo:

O reconhecimento e a delimitação do espaço rural variam [...] em função das formas efetivas de ocupação territorial, da evolução histórica e das concepções predominantes em cada um deles [...] Assim tradicionalmente, a agricultura constituía o elemento configurador central do espaço rural e os agricultores, mesmo habituados a conviver com outros indivíduos e categorias sociais, sempre foram percebidos como o esteio econômico, social e cultural do meio rural [...] Na atualidade, a agricultura continua, sem dúvida, a desempenhar um papel relevante [...] No entanto, o modelo produtivista entrou em crise a partir dos anos 1980. 0 sucesso, inegável, da modernização da agricultura, gerou, ao mesmo tempo, suas próprias crises [...] o sucesso do processo de modernização, especialmente no que se refere aos índices de produtividade atingidos, teve como resultado a redução da necessidade de força de trabalho ocupada nas atividades agrícolas. Com efeito, o aumento da produtividade do trabalho, no conjunto das atividades agropecuárias, terminou por tornar desnecessária à produção, parcela importante dos efetivos de agriculturas, problema tanto mais grave quanto a conversão para o trabalho nos setores industrial ou de serviços deixou de ser uma possibilidade em razão da própria dimensão da crise geral do desemprego.
De posse desta breve exposição do espaço rural, salienta-se que o turismo rural contempla uma nova forma de valorizar e ao mesmo tempo diversificar a atividade no meio rural. De acordo com o Ministério do Turismo (2004, p. 15):

\begin{abstract}
Embora a visitação a propriedades rurais seja uma prática antiga e comum no Brasil, esse deslocamento para áreas rurais começou a ser encarada com profissionalismo na década de 1980, quando algumas propriedades em Santa Catarina e no Rio Grande do Sul, devido às dificuldades do setor agropecuário, resolveram diversificar suas atividades e passaram a receber turistas.
\end{abstract}

Conforme afirma Castrogiovanni (2009, p.60), a ampliação do enfoque, bem como da atividade turística denota a concepção de que:

Hoje, há uma certa tendência em ampliarmos o conceito de turismo, uma vez que deve ser visto como uma atividade econômica e como uma atividade humana. Ao se apoiar em dois grandes pilares (o motivo da viagem e a viagem em si), constitui-se como um importante ponto de ruptura epistemológica com as anteriores formas de antever o turismo a percepção estrita de turismo enquanto viagem recreativa ou de lazer substitui-se por uma visão abrangente, na qual deve ser considerada uma multiplicidade de motivações pessoais [...]

Deve-se ressaltar que o turismo rural como fenômeno, apresenta-se como uma potencial alternativa para muitos espaços rurais, e vem cada vez mais crescendo em proporção e importância, à medida que permite a valorização do meio rural, tanto por meio do apelo à natureza e seus potenciais paisagísticos, como pelas características das sociedades modernas, de maior facilidade no tocante aos transportes e comunicações, características cada vez mais acentuadas nas últimas décadas.

Como atividade que perfaz uma das formas pela qual o espaço rural apresenta a sua diversificação espacial, “[...] 0 consumo do espaço é hoje um tema que renova os parâmetros da relação da soci-

\footnotetext{
${ }^{5}$ Por desenvolvimento rural, compreende-se uma complexa e multidimensional abordagem, na qual, as heterogeneidades geográficas, históricas e ocupacionais constroem diferentes trajetórias que devem ser levadas em conta nas estratégias a serem adotadas (KAGEYAMA, 2008)

${ }^{6} \mathrm{~A}$ Revolução Verde representa um dos principais esforços para internacionalizar o processo de apropriacionismo. A realização científica decisiva foi a difusão das técnicas de criação de plantas desenvolvidas na agricultura de clima temperado, para o meio ambiente das regiões tropicais e subtropicais. Entretanto, a força que impulsionou este processo se manteve inalterada: controlar e modificar os elementos do processo biológico de produção que determinam o rendimento, a estrutura da planta, a maturação, a absorção de nutrientes e a compatibilidade com os insumos produzidos industrialmente... o conhecimento teórico e prático para esta tarefa já tinha sido estabelecido. Portanto, em grande medida, a Revolução Verde, através da difusão internacional das técnicas da pesquisa agrícola, marca uma maior homogeneização do processo de produção agrícola em torno de um conjunto compartilhado de práticas agronômicas e de insumos industriais genéricos. (GOODMAN, et. al., 1990, p. 34).
} 
edade com o seu espaço... A alma do rural mantém uma forte coloração agrícola, embora o bolso dependa, cada dia mais acentuadamente, de outros proventos [...] (BAPTISTA, 2006, p. 97 - 100)".

Neste sentido, o turismo enquanto agente responsável pelo novo cenário no espaço rural deve ser incluído como atividade complementar as práticas agrícolas, evitando a desestruturação da cadeia produtiva local, bem como outras situações como os impactos de diversas ordens sobre os recursos naturais, ou ainda prejuízo às tradições e autenticidade dos espaços locais. Conforme destaca Campanhola e Graziano da Silva (2000, p. 65): "[...] se a atividade turística não for planejada e fiscalizada pela população e pelo poder público local, ela pode acarretar impactos indesejados sobre o meio ambiente, sobre a economia e a sociedade local".

Ponderando-se acerca do potencial de revalorização de locais e espaços ímpares contidos no mundo rural, Abramovay (2003) destaca o fato desta atividade enaltecer aspectos potenciais sociais e culturais do início deste século, afirmando que:

\footnotetext{
Uma visão territorial do desenvolvimento pode revelar potenciais que, até hoje, o meio rural não revelou à sociedade. Visto como a base física da produção agrícola, seu destino dificilmente escapa à tragédia do esvaziamento social, econômico, político e cultural. Quando, entretanto, o meio rural é encarado, não como a simples sustentação geográfica de um setor (a agricultura), mas como base de um conjunto diversificado de atividades e de mercados potenciais, seus horizontes podem ser ampliados (ABRAMOVAY, 2003, p. 98).
}

Outro autor que igualmente também corrobora com tais constatações é José Eli da Veiga ao afirmar que nos últimos tempos "as principais vantagens comparativas voltaram a ser riquezas naturais, mas de outro tipo. São os encantos do contexto rural - beleza paisagística, tranquilidade, silêncio, água limpa, ar puro - todas ligadas à qualidade do meio ambiente natural" (VEIGA, 2004, p. 63).

Cabe salientar que o termo turismo em áreas rurais é expresso como atividade turística praticada e vinculada com o espaço rural, podendo se expressar independente de sua relação com as atividades propriamente agrárias (mesmo que na maior parte dos exemplos visualizados envolvem comercialização, apresentação de cultivos e práticas agrícolas).

Algumas terminologias que se apresentam como segmentos turísticos são denominados como: Turismo Rural - caracterizado pela prática de atividades recreativas que se vinculam a "lidas" e costumes característicos do rural; o Turismo Ecológico - que apresenta atividades vinculadas à natureza; o Turismo Cultural - que busca apresentar e a medida do possível aproximar o turista a uma determinada cultura; o Turismo Histórico - focado no resgate e (re)criação de aspectos históricos do espaço visitado, atividade que normalmente está intimamente vinculado com o turismo cultural.

Existem ainda outras modalidades de turismo, ações que igualmente podem ser praticadas em espaços rurais. Sendo que estas modalidades de turismo podem ser exploradas conjuntamente ou individualmente. Porém, mesmo diante de diferenciações cunceituais, Tulik (2003) ao abordar o conceito da terminologia "Turismo em Espaços Rurais", coloca este como sendo a totalidade das atividades turísticas desempenhadas no meio rural, ainda que comumente ocorra o emprego do termo turismo rural como sinônimo de turismo em espaços rurais, não sendo considerado, portanto, um "erro" tal expressão.

De forma geral, na atividade denominada Turismo Rural, observa-se que a demanda vem fugindo do turismo massificado, dominado por grandes empresas hoteleiras e de transporte. Neste sentido Alves (2006, p. 29) afirma que:

\begin{abstract}
Pessoas cansadas da despersonificação das grandes cidades buscam nos ambientes rurais um modo de vida mais autêntico. 0 excesso de paisagens construídas das metrópoles leva a uma busca pela paisagem natural. A mesmice dos produtos padronizados dá lugar a uma busca de produtos com identidade própria, com vínculos locais.
\end{abstract}

Tão logo a atividade turística nesses espaços associam uma demanda tipicamente urbana, conduzida pela paisagem rural, atributos naturais, produtos, cultura, ou ainda, outras relações internas e peculiares ao âmbito social que passam a adquirir ampla relevância. Trata-se, portanto, de novas formas de relações e inter-relações entre espaços rurais e urbanos, relações estas que apresentam necessidades diferenciadas nas formas de vislumbrar e encarar estilo, padrões e planejamentos no âmbito do local em que a mesma se manifesta, pois,

As localidades geográficas possuem especificidades, com contradições e conflitos próprios, que se derivam da relação entre sistema de valores e interesses diversos, tanto de origem urbana como rural. Esse processo de interação contínua entre as forças sociais, econômicas e políticas, na 
maioria das vezes, conduz a uma reorganização do espaço de acordo com um ou outro interesse ou projeto final, mas é, entretanto, o que faz surgir as formas sociais existentes (SOUZA, 2004, p. 40).

Com base nestes aspectos, e resguardadas as devidas atenções necessárias à inserção da atividade turística como alternativa aos espaços rurais, destaca-se a importância da mesma através de sua relevância socioeconômica, mesmo diante de problemáticas envolvidas e/ou relacionadas diretamente a atividade como a sazonalidade da produção, os riscos eminentes aos impactos de cunho ambiental e cultural, e as incertezas voltadas a (re)alocação dos fatores de produção localmente existentes. Este último aspecto ressaltado, ainda que potencialmente nocivo no sentido da alocação da mão de obra, pode também incorporar possibilidades que aglutinem geração de empregos no campo, uma vez que se observa a diminuição dessa demanda.

Um exemplo palpável de tais potenciais pode ser verificado no aumento e melhorias que cada vez mais indivíduos têm procurado incorporar as suas propriedades, ou seja, a agroindústria. Conforme aponta Pelegrini e Gazolla, esse processo poderia gerar vários benefícios a produção agrícola do produtor, sobretudo quando havendo consumidores em potencial como no caso da atividade turística, uma vez que garantiria maior durabilidade da matéria prima para comercialização, bem como maior independência por parte destes em relação a mercados pré-estabelecidos, abrindo margem para a busca de novos mercados via busca de novos consumidores. Nesse sentido cabe salientarque:

[...] o processo de agroindustrialização de um determinado produto é desenvolvido na medida em que este produto é conhecido e encontra-se disponível, também é indispensável que exista a necessidade real da sua transformação e os meios necessários para efetivá-la. Um dos objetivos históricos da transformação dos alimentos é o de se obter uma maior conservação, indispensável para manter os alimentos disponíveis ao consumo em períodos de escassez. De outra forma, serve para concentrar os nutrientes, originando alimentos de maior valor nutritivo, facilitando assim, o consumo e o transporte. (PELEGRINI; GAZOLLA, 2008, p. 56).

Diante dos aspectos acima descritos, vislumbra-se o turismo no espaço rural como atividade capaz de contribuir com a dinâmica contempo- rânea do campo. Assim sendo, impacta direta e/ou indiretamente o cotidiano dos atores do mundo rural à medida que oferece oportunidades e consolida desafios, desafios estes que, quando bem planejados e gestionados podem minimizar os aspectos negativos e potencializar suas implicações positivas.

\section{Percepção dos agricultores sobre a implanta- ção do turismo rural em seus respectivos esta- belecimentos}

De características basicamente agrícolas, o rural do Município de Paim Filho/RS é caracterizado por pequenos estabelecimentos. Considerando os agricultores da pesquisa, predominam os estabelecimentos entre quatro e dez hectares (FIG. 2). No entanto, é importante ressaltar que estes estabelecimentos reúnem as características procuradas pelos adeptos do turismo rural, ou seja, recursos naturais exuberantes e famílias que mantém um estilo de vida tradicional.

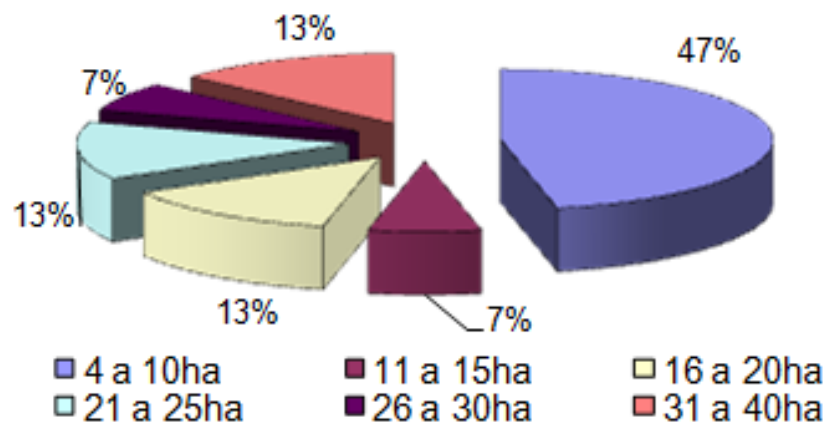

Figura 2 - Tamanho estabelecimento agrícola. Fonte: Trabalho de campo.

Ainda que alguns agricultores desenvolvam atividades relacionadas ao turismo rural, os mesmos ainda continuam atuando na agricultura. No entanto, esses agricultores manifestam as dificuldades de atuar no segmento agrícola, principalmente devido à complexidade das atividades, assim como as sucessivas crises enfrentadas nos últimos anos. De um modo geral os agricultores apontam as questões climáticas, seguida dos altos custos dos insumos como as principais razões da(s) situação(ões) de crise (FIG. 3).

Em decorrência da degradação ambiental e do aquecimento global, as crises provocadas por eventos climáticos tendem a se intensificar ao longo dos anos. Assim, é possível que a renda advinda das atividades agrícolas tenda a ser afetada, principalmente no longo prazo, podendo comprometer financeiramente o agricultor. 


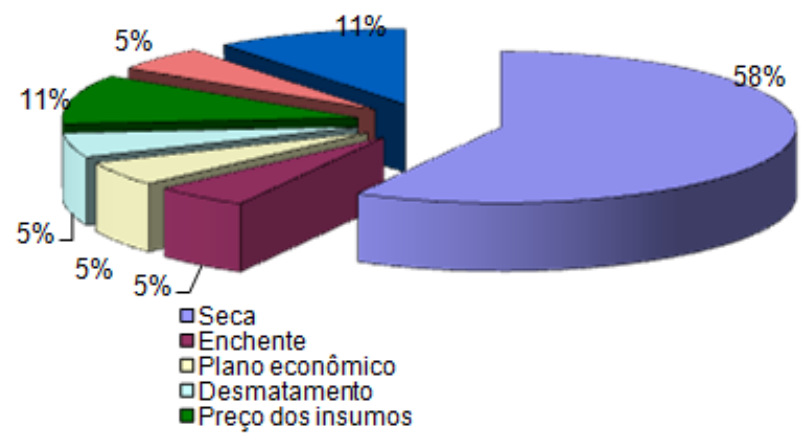

Figura 3 - Crises enfrentadas nos últimos cinco anos. Fonte: Trabalho de campo.

No caso específico dos agricultores entrevistados, fica evidente a busca por alternativas para a(s) crise(s), a exemplo do ano de 2005, quando o Rio Grande do Sul foi atingindo por uma estiagem prolongada no período de verão. Nesse período, a alternativa econômica cunhada se deu através da comercialização de produtos de subsistência que foram menos impactados, dentre os quais se destacou a comercialização de derivados de leite, onde os turistas tiveram importância no papel de demandantes de tais produtos.

Distintas alternativas não vinculadas ao setor turístico foram efetuadas. Uma destas ações foi a tomada de empréstimos financeiros, escolha esta que não contemplou a maioria dos proprietários rurais, já que a maior parcela evitou fazer novos investimentos no estabelecimento, diminuindo os gastos com a lavoura, bem como despesas domésticas. Outras ações nesse sentido foram o arrendamento das terras e os empregos externos a propriedade, alternativas estas que mesmo não culminando com o abandono das atividades agrárias, reduziram a ocupação e os investimentos na propriedade como um todo, além da renda bruta dos indivíduos conforme relatos coletados.

Diante deste cenário e frente às características históricas do Município as atividades desenvolvidas nos estabelecimentos se apresentaram bastante diversificada conforme se observa na Figura 4.

Foi constatado, durante as entrevistas, que em três propriedades a quantidade de água é abundante, são provindas de fontes e nascentes locais e são destinadas principalmente para irrigar plantações. Essas fontes e nascentes, não secam durante as estiagens. Essa realidade explica porque alguns agricultores afirmaram não terem sofrido nenhuma crise nos últimos cinco anos.

Como a maioria informou que comercializava os produtos de subsistência durante os anos de crise, ficou visível as problemáticas da região e os impactos frente as culturas locais, característica dos pequenos estabelecimentos da região. Além disso, a produção agrícola como milho, soja, trigo e feijão foram às opções que apareceram em todas as entrevistas, em segundo lugar está a produção leiteira, que aparece juntamente com a produção de derivados agrícolas (FIG. 4).
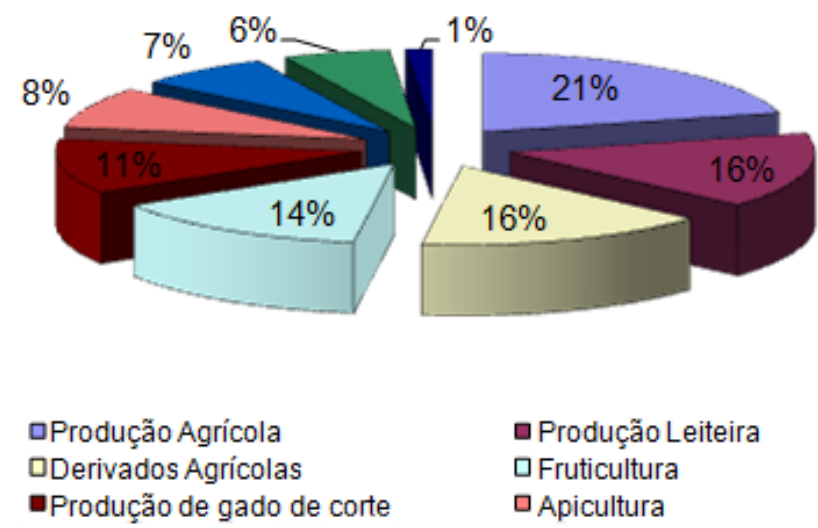

Figura 4 - Principais atividades desenvolvidas nos estabelecimentos rurais. Fonte: Trabalho de campo.

Entre os derivados agrícolas produzidos, destaca-se o queijo, açúcar mascavo, melado, geléias, rapadura, compota, suco de uva, conservas, salame. Algumas propriedades rurais possuem alambique e cantina, que também é um atrativo para os turistas rurais que desejam conhecer a produção de cachaça, de vinho e realizar a degustação. Também há uma agroindústria que produz açúcar mascavo, rapadura, melado e cachaça, todos esses produtos feitos com matéria-prima orgânica. Estas agroindústrias parecem desenvolver um papel central nestas propriedades, já que:

\footnotetext{
Através da análise da agricultura familiar constata-se que a agroindústria familiar passa a ser uma estratégia de reprodução social das famílias rurais. Estas sofrem influência de inúmeros fatores socioeconômicos que afetam o processo de constituição e estruturação das agroindústrias familiares. Estes fatores são mencionados por diversos estudos [...] A agroindustrialização dos alimentos não pode ser entendida como sendo um fato em si, deve ser considerada como um processo que se relaciona à reprodução e sobrevivência do grupo que a pratica. Os produtos utilizados na alimentação humana foram sendo descobertos e introduzidos nos hábitos alimentares e, com o passar dos anos, através da sua transformação ganharam novas configurações para o consumo e para armazenagem. (PELEGRINI; GAZOLLA, 2008, p. 55-56).
} 
Tal realidade de potenciais de ganhos e a vinculação com as configurações locais de cultura e sociedade pode ser observada na forma como a maior parcela desses produtos é comercializado, ou seja, diretamente ao consumidor, fidelizando o mesmo e criando uma identidade do produto. Nesse contexto á pratica do turismo rural, contribui para expandir a produção e, consequentemente, a comercialização que com o aumento do número de visitantes também tende a se expandir.

Além dos alimentos, também existem atributos naturais que possibilitam a prática do turismo. Assim, quando questionados acerca do que suas propriedades oferecem de recursos naturais, os proprietários rurais de Paim Filho apresentaram um leque de possibilidades, conforme apresenta a Figura 5.

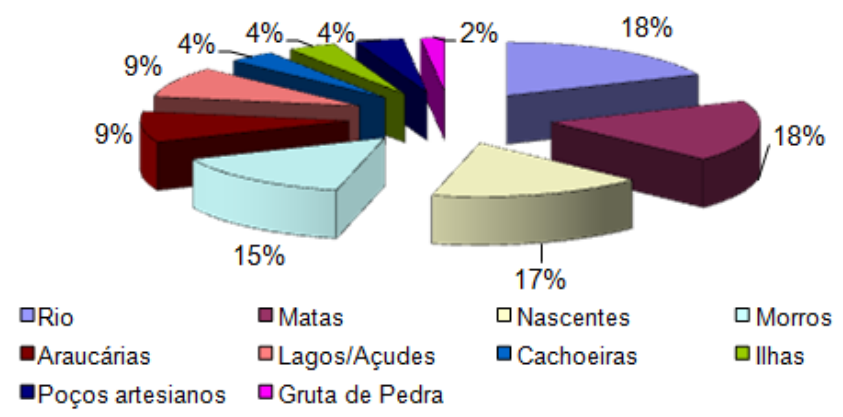

Figura 5 - Recursos naturais identificados nos estabelecimentos rurais. Fonte: Trabalho de campo.

A diversidade de recursos naturais identificados denota que os estabelecimentos rurais locais são possuidores de muitos atributos (potenciais), apresentando além de matas, rios e lagos (elementos característicos da maior parte das propriedades que ofertam turismo no espaço rural), outros atrativos diferenciados como grutas, morros, araucárias e ilhas, realidade que contribui para atrair turistas interessados no espaço rural.

Dentre esta gama de atrativos, são as matas, os rios, as nascentes e os morros aqueles mais destacados pelos proprietários $(18 \%$ o primeiro e o segundo atrativo; $17 \%$ o segundo e $15 \%$ o último recurso citado). A lembrança por tais atributos possui uma estreita relação com a disponibilidade, já que os demais atrativos lembrados são visualizados apenas em algumas propriedades, não sendo a realidade da maior parte dos ofertantes de serviços turísticos.

Quando solicitados a comentar sobre os cuidados com esses recursos naturais, os mesmos responderam que não plantam e não aplicam agrotóxicos próximos às fontes, rios e açudes. A maior parte deles afirmou também ter preocupação com a preservação das matas ciliares e encostas dos morros. A intenção dos proprietários em seus estabelecimentos é o reflorestamento com espécies nativas, conforme exigências do IBAMA (Instituto Brasileiro do Meio Ambiente e dos Recursos Naturais Renováveis).

Alguns empreendedores têm sinalizado sua propriedade com placas que alertam para a conservação, higiene e limpeza do local. Os que moram próximo aos Balneários, recolhem o lixo trazido pela água e cuidam do visual da propriedade, dos jardins, da limpeza, além de distribuir lixeiras por onde os turistas passam. Muitos destes proprietários vêm proibindo a caça no local.

Um elemento importante a ser considerado para a prática do turismo rural e presente entre os entrevistados está o estilo de vida das famílias. Em relação à estrutura produtiva destacam-se o uso de sementes crioulas ${ }^{7}$ e a produção de erva no carijo $^{8}$. A organização do trabalho no estabelecimento pouco mudou, as mulheres cuidam dos filhos, preparam as refeições e ajudam na lavoura. Os homens por sua vez trabalham no plantio, criação dos animais e comercialização dos produtos. A ênfase para o estilo de vida dos agricultores como um atrativo a ser considerado na atividade turística corrobora com a observação das estruturas da sede do estabelecimento, onde $47 \%$ dos estabelecimentos ainda preservam as casas em estilo colonial.

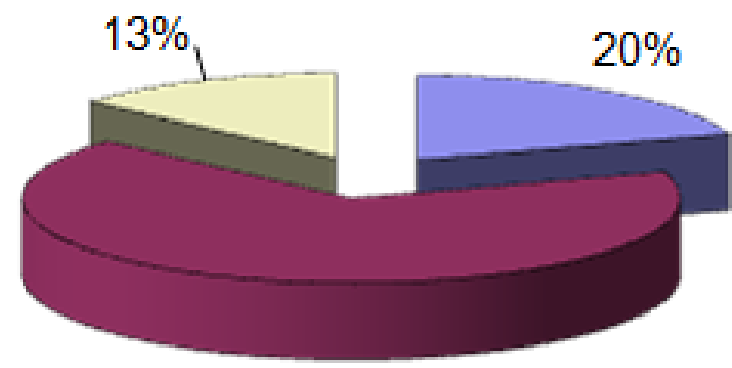

$67 \%$

\section{口Um ou dois \\ 口Cinco ou seis}

Figura 6 - Número de pessoas que residem nas propriedades. Fonte: Trabalho de campo.

\footnotetext{
${ }^{7}$ Também conhecidas como sementes domesticadas ou caseiras, as variedades de sementes crioulas sobrevivem há várias gerações, principalmente na base da troca, e ainda são usadas no sistema tradicional de agricultura.

${ }^{8} \mathrm{O}$ carijo é uma instalação de madeira, coberta de tábuas ou telhas, aberta dos lados. Nessa instalação, os feixes de erva sapecada são colocados sobre uma espécie de varal e submetidos ao calor provocado por uma fogueira para a secagem definitiva.
} 
A organização familiar, de um modo geral contempla uma situação particular. Embora prepondere em $67 \%$ dos estabelecimentos uma média de três a quatro residentes, a mão de obra disponível no estabelecimento tende a estar abaixo desse percentual. Além dos responsáveis pelo estabelecimento, é comum residir na mesma casa pessoas idosas que não se constituem enquanto mão de obra efetiva (sobretudo em função de problemas de saúde), não podendo assim ser considerados como recurso humano para as atividades rurais, nem mesmo para serviços voltados a atividades turísticas (FIG. 6). Por outro lado, os jovens raramente permanecem no estabelecimento, uma vez que se deslocam e fixam residências em municípios maiores com o objetivo de trabalhar em serviços urbanos ou para fins de estudo.

Neste contexto, uma das grandes dificuldades para os agricultores que ensejam trabalhar com o turismo rural em seus respectivos estabelecimentos esbarra na falta de mão de obra disponível assim como na qualificação dos recursos para atender adequadamente os turistas. Mesmo com a atividade tendo se expressado de forma mais rentável, ainda é escasso o número de jovens que visualizam a sucessão rural nas propriedades.

No que se refere à inserção na comunidade, os agricultores considerados na pesquisa expõem que as famílias são unidas, dialogam e interagem através de jogos como o baralho, através do truco, quatrilho, 3/7; jogos em quadras, como o futebol, a bocha e o bolão; e a religiosidade, onde se destacam as festas ao Santo Padroeiro de cada comunidade e as novenas. As mulheres reúnem-se ainda para confeccionar artesanatos como vassouras de palha, chapéu de palha, crochê, tricô; também na troca e provação de receitas; rodas de chimarrão, cantigas italianas, carneação. Algumas ainda responderam que a confecção do filó ${ }^{9}$, prática muito comum no passado e que vem sistematicamente sendo abandonado.

Todos os aspectos acima citados podem ser explorados enquanto atrativos para visitantes externos que vêem nos costumes locais elementos voltados à tradição que lhes desperta curiosidade e interesse, podendo assim se concretizar como um produto turístico não palpável, mas rentável e potencial ao comércio de produtos e alimentos (agroindustrializados ou não).

De um modo geral, a análise das entrevistas junto aos agricultores considerados na pesquisa permite inferir que em todos os estabelecimentos, em maior ou menor grau, identifica-se algum potencial, seja através das paisagens naturais, da produção de produtos caseiros ou das pequenas agroindústrias e pelo estilo de vida. Estes elementos resguardam tradições e costumes de seus antepassados, que permite ou são compatíveis com a prática do turismo rural.

Dentre as oportunidades que estão sendo aproveitadas e com potencial de expansão têm-se a comercialização dos produtos caseiros, a disponibilização de casas para alugar e áreas de camping, próximos às áreas com belezas naturais. 0 artesanato e a agroindústria caseira também se constituem em oportunidades de negócio que precisam ser trabalhadas.

Em relação às dificuldades, figuram nos estabelecimentos a necessidade de aporte financeiro para a realização de investimentos em infraestrutura. Contudo, os agricultores são enfáticos em afirmar que o principal entrave está na disponibilidade de mão de obra, bem como a qualificação e capacitação dos recursos humanos para atuar de forma organizada, primando pelo atendimento aos turistas. A partir disso, muitos revelaram possuir "medo de não poder e/ou saber atender adequadamente os turistas".

Em relação ao ambiente externo, uma das principais dificuldades consiste nas dificuldades de acesso aos estabelecimentos e/ou locais de comercialização de produtos caseiros. Neste contexto, as pessoas e/ou turistas que visitam o município tem dificuldades para encontrar os locais onde estes produtos são feitos e comercializados, pois não existe sinalização indicativa e nem divulgação adequadas dos referidos locais. Nesse sentido, os agricultores estão conscientes e manifestam que o segmento do turismo rural depende também do apoio do Poder Público, no sentido de melhorias de infra-estrutura, principalmente da abertura e manutenção de vias de acesso, para facilitar o trânsito de turistas.

Mesmo diante das dificuldades dos agricultores em atuar no segmento de turismo, é importante ressaltar que mais de $85 \%$ deles se dizem entusiasmados, manifestam interesse em permanecer e ampliar a oferta do serviço. Destarte, alguns já realizaram investimentos em infraestrutura para receber turistas. É importante salientar que os agricultores são unânimes em considerar o turismo rural uma atividade complementar, que conjugada com outras atividades pode contribuir para a diversificação das atividades, na agregação de renda e na reprodução social da família, realidade que valoriza a produção agrária e a propriedade

\footnotetext{
${ }^{9}$ Encontro entre duas ou três famílias em casa particular, que ocorre no período da noite, com o objetivo de conversarem e se divertirem.
} 
como um todo.

Quanto ao Poder Público do Município de Paim Filho, mesmo não existindo uma atuação estratégica específica com o objetivo de fomentar a prática do turismo no espaço rural, os agricultores vêm realizando algumas iniciativas no sentido de melhorar a interação com os turistas. Essas iniciativas também estão relacionadas com o entendimento dos agricultores em relação à necessidade de diversificação das atividades como uma estratégia de ingresso de rendas, bem como a necessidade em proporcionar benefícios aos estabelecimentos, tanto pela renda da atividade quanto pela comercialização de produtos agropecuários.

\section{Considerações finais}

O turismo rural vem se constituindo numa alternativa para os empreendimentos agrícolas, principalmente aos pequenos agricultores, que permanentemente estão submetidos ao risco e à incerteza dos fatores de produção. Além de proporcionar um aumento na renda e ocupar a mão de obra familiar, as famílias interagem socialmente e culturalmente com um público diversificado, aproveitam espaço e tempos ociosos e amenizam os problemas da sazonalidade das atividades rurais.

A iniciativa turística junto aos agricultores interessados em desenvolver atividades associadas a este setor de serviços, se combinadas com projetos e políticas públicas adequadas, pode se tornar um excelente instrumento de desenvolvimento rural favorecendo principalmente os pequenos agricultores. A implantação de atividades alternativas àquelas essencialmente agrícolas tende a diversificar as fontes de renda, reduzir o risco (oriundo principalmente das questões climáticas) e ainda, contribuir na diminuição do êxodo rural.

Dessa forma, o espaço rural do município de Paim Filho-RS pela forma que é composto, ou seja, basicamente por pequenos estabelecimentos agrícolas, vislumbra no turismo rural uma alternativa de geração de trabalho e renda ao espaço rural. Destarte, além de ocupar a mão de obra familiar e reduzir a migração dos filhos, é capaz de aumentar a probabilidade de melhorar a situação econômica.

Salienta-se ainda, que a maior parte dos proprietários rurais envolvidos na pesquisa apresentou condições (mesmo diante de debilidades existentes) e interesse em manter conjugadas na sua propriedade a agropecuária com a atividade turística. Pode-se apontar portanto, que os agricultores estão dispostos a atuar nessa atividade, que se bem conduzida, pode servir como alternativa socioeconômica ao rural do Município. Em relação às limitações, existe a necessidade da realização de investimentos em infraestrutura nas propriedades e a qualificação dos recursos humanos para a recepção dos visitantes, oferta de mais informações e serviços, além da ampliação da mão de obra local devido a redução da população rural (fruto do êxodo) ocorrida sobretudo das décadas passadas.

\section{Referências}

ABRAMOVAY, R. o futuro das regióes rurais. Porto Alegre: UFRGS, 2003.

ALMEIDA, J. A. Pesquisa em extensão rural. Um manual de metodologia. Brasília: Associação Brasileira de Educação Agrícola Superior, 1989.

ALVES, H. F. I. Turismo e Desenvolvimento: A Dimensão Cultural - Serra da Mantiqueira (MG). Santa Maria: FACOS - UFSM, 2005. (Série Dissertações em Turismo Rural, 10).

BAPTISTA, F. O. O Rural depois da Agricultura. In: Desenvolvimento e território: Espaços rurais pósagrícolas e novos lugares de turismo e lazer. Lisboa: M2 Artes Gráficas, Ltda, p. 85 - 105, 2006.

BRASIL, Ministério do Turismo. Diretrizes para o Desenvolvimento do Turismo Rural no Brasil. 2004. Disponível em: <http://www.turismo.gov.br>. Acesso em:20 mar. 2007.

CAMPANHOLA, C., GRAZIANO DA SILVA, J. O Agroturismo como nova forma de renda para o pequeno agricultor brasileiros. In: ALMEIDA, J. A.; RIEDL, M. Turismo Rural: Ecologia, Lazer e Desenvolvimento. São Paulo: EDUSC, 2000.

CAPORAL, F. R.; COSTABEBER, J. A. Agroecologia e extensão rural: contribuições para a promoção do desenvolvimento rural sustentável. Brasília: MDA/SAF/DATER-IICA, 2004.

CASTROGIOVANNI, A. C. (Pre)Ocupações com o turismo rural. In: MEDEIROS, R. M. V.; FALCADE, I. (Org.). Tradição versus tecnologia: as novas territorialidades do espaço agrário brasileiro. Porto Alegre: Ed. da UFRGS, 2009.295 p. p. $59-66$.

CONTERATO, M.; FILLIPI, E. E. Teorias do desenvolvimento. Porto Alegre: Ed. da UFRGS, 2009.

DIAS, R. Planejamento do Turismo: política e desenvolvimento do turismo no Brasil. São Paulo: Atlas, 2003.

GOODMAN, D.; SORJ, B.; WILKINSON, J. Da lavoura às biotecnologias. Rio de Janeiro: Campus, 1990. 
IBGE - Instituto Brasileiro de Geografia e Estatística. Cidades@. Disponível em: <http:// www.ibge.gov.br/cidadesat/topwindow.htm?1>. Acesso em: 10 de jan. 2012.

KAGEYAMA, A. A. Desenvolvimento rural: conceitos e aplicação ao caso brasileiro. Porto Alegre: Ed. da UFRGS, 2008.

PELEGRINI, G.; GAZOLLA, M. A agricultura familiar no Rio Grande do Sul: limites e potencialidades a sua reprodução social. Frederico Westphalen: Ed. da URI, 2008.

RUSCHMANN, D. van de M. Turismo rural e o desenvolvimento sustentável. In: ALMEIDA, J. A.; FROEHLICH, J. M. RIEDL, M. (Orgs.). Turismo rural e desenvolvimento sustentável. 4. ed. São Paulo: Papirus, 2004.
SOUZA, M. Pluriatividade e nova ruralidade: reelaboração de identidades sociais em duas comunidades paranaenses. In: CAMPANHOLA, C.; SILVA, J. G. O novo rural Brasileiro: Novas ruralidades e urbanização. Brasília: Embrapa, 2004.p.39-69.

TULIK, Olga. Turismo Rural. São Paulo: Aleph, 2003.

VEIGA, J. E. Destinos da ruralidade no processo de globalização. Estudos Avançados, São Paulo, n. 5, p. 51-67, 2004.

WANDERLEY, M. de N. B. 0 mundo rural como um espaço de vida: reflexões sobre a propriedade da terra, agricultura familiar e ruralidade. Porto Alegre: Ed. da UFRGS, 2009.

\title{
Rural tourism in the municipality of Paim Filho/RS/Brazil: potentialities, alternatives and benefits from the generation of work and finances in the rural space
}

\begin{abstract}
The rural tourism has been constituted as a potential activity of transformations in agriculture, agricultural products price oscillations, sazonality problems, besides the risks and uncertainties in relation to production factors. In this sense, this work aims to identify the potentialities and difficulties related to the offer of rural tourism in agricultural establishments in the municipality of Paim Filho/RS, verifying the potential benefits of this activity. Methodologically, a bibliographic search was followed by data collection, applying questionnaires and interview in 15 rural establishments located in the city. The results show that the approached establishments present conditions of exploration as a touristic product, either through their natural beauties, or through the life style which preserves traditions and costumes. Among the agriculturists considered, more than $85 \%$ manifested interest in follow acting in the rural tourism segment, with some of them having actually performed investments in infrastructure for receiving visitants. We also emphasize that the local actors are unanimous in considering the tourism a possibility of complementary activity, which can contribute to the social reproduction of the family once joined which other activities. In relation to the limitations, there is a need of infrastructure and human-resources investment, besides the increase in workmanship. We conclude that the rural tourism presents as a potential alternative for work and finances generations, that could afford benefits to the establishments, both for the finances generated from the activity and for the agricultural products commercialization.
\end{abstract}

Keywords: Rural Tourism. Touristic Potential. Generation Of Work And Finances. 